\title{
Drug Release OFF Behavior and Deswelling Kinetics of Thermo-Responsive IPNs Composed of Poly(acrylamide-co-butyl methacrylate) and Poly(acrylic acid)
}

\author{
Hiroki Katono, Kohei Sanui, Naoya Ogata, Teruo Okano, ${ }^{*, \dagger}$ \\ and Yasuhisa SAKURAI* \\ Department of Chemistry, Faculty of Science and Technology, \\ Sophia University, Chiyoda-ku, Tokyo I02, Japan \\ *Institute of Biomedicai Engineering, Tokyo Women's Medical College, \\ Shinjuku-ku, Tokyo 162, Japan
}

(Received March 18, 1991)

\begin{abstract}
Interpenetrating polymer networks (IPNs) composed of poly(acrylamide(AAm)co-butyl methacrylate (BMA)) and poly(acrylic acid) (PAAc) demonstrate positive swelling changes with an abrupt transition as temperature increases. Temperature-modulated controlled drug release using swelling-shrinking responses of the hydrogels as on-off switches for drug release is reported. The IPNs demonstrate "on" release at higher temperatures. When changing from higher to lower temperatures, an immediate pulsatile drug release is observed followed by a nearly complete "off" state of drug release. The drastic increase of drug release rate is due to mechanical squeezing by a shrinking gel surface layer of the IPNs in response to decreasing temperature. The following decrease of drug release is due to a subsequent formation of a dense layer of polymer at the IPN surface.
\end{abstract}

KEY WORDS Temperature Responsive Hydrogel / Interpenetrating Polymer Network / Hydrogen Bond / Polymer-Polymer Complex / Pulsatile Drug Release / Shrinking Mechanism / Surface Shrinking Layer / Squeeze Effect / Self-Regulating Drug Release /

Polymeric materials able to exhibit specifically designed, sequential functions as sensors, processors and actuators should be termed "intelligent materials." Such intelligent materials are the best candidates to achieve ideal auto-feed back systems and/or self-regulating systems for drug delivery. In this perspective, stimuli-sensitive hydrogels showing reversible swelling changes in response to external stimuli have been investigated for medical use. Fundamental investigations of swelling-shrinking behavior of gels have been developed by many scientists utilizing of varied stimuli. ${ }^{1-11}$ Some gels demonstrate swelling changes in response to changing external conditions, including $\mathrm{pH},{ }^{1}$ electric current,${ }^{2}$ chemicals, ${ }^{3}$ osmotic strength, ${ }^{4}$ solvent composition, ${ }^{5-8}$ and temperature. ${ }^{10-19,21-24}$ These gels also show reversible swelling change. Since gel swelling changes enable regulation of drug diffusivity within the gel, regulation of on-off drug release or release rates may be achieved by utilizing swelling-shrinking changes induced in gels.

A series of studies on thermo-sensitive gels and their possible applications to medical treatment have been published recently by Okano and coworkers. They have shown thermoresponsive pulsatile on-off drug release systems using gels containing poly $(N$-isopropylacryl-

\footnotetext{
$\dagger$ To whom correspondence should be addressed.
} 
amide) (PIPAAm), demonstrating a lower critical solution temperature (LCST). ${ }^{12,14-16}$ They have also proposed that the switching temperature for on-off drug release be controlled by adjusting the amount of hydrophobic component incorporated as a comonomer into PIPPAm gels. ${ }^{14}$ Furthermore, the on-off drug release mechanism responding to temperature changes in these gels has also been discussed and elucidated.

Another approach to producing hydrogels which show temperature dependent swelling changes utilizes temperature-dependent, reversible polymer-polymer interactions. Hydrogels constructed from two types of polymers which have temperature dependent-attractive or repulsive forces may show significant swelling changes with temperature changes. Bae et al. ${ }^{11}$ reported swelling behavior of interpenetrating polymer network (IPN) which shows swelling change induced by repulsive force between polymers - one composed of poly(ethylene oxide) (PEO) and polyacryloylpyrrolidine (PApy). The IPN reportedly shrinks at higher temperatures and swells at lower temperatures. Swelling ratios of the IPN at lower temperature are much higher than that of homopolymer gels. The high swelling at lower temperatures is induced by an interpolymer repulsive force between PEO and PApy.

Contrary to the case mentioned above, temperature dependent attractive forces between polymers can also cause swellingshrinking changes with dramatic transitions. We have already obtained a hydrogel which shows low swelling at lower temperatures and high swelling at higher temperatures exhibiting such a transition. The gel is an IPN composed of two kinds of polymers such as poly(acrylic acid) (PAAc) and polyacrylamide (PAAm) which form an interpolymer complex by hydrogen bonding and precipitate only at lower temperatures. The complex disssociates at higher temperatures due to breakage of hydrogen bonds. ${ }^{20}$ The two states of polymer interaction, i.e., complex formation and complex dissociation, change across a narrow temperature range, demonstrating a sudden transition, not gradual alteration. We have already shown that, in fact, IPNs constructed from these two polymers contract at lower temperature and swell at higher temperature, exhibiting dramatic transitions with temperature changes, through rapid polymer complex formation and dissociation.

It is generally known that the release rate of solute from a hydrogel matrix into media depends on swelling ratio of the gel. Dependence of release rate on the equilibrium swelling ratio can be easily evaluated by measuring release rate at the constant condition. However, mechanism of release rate change and change of concentration distribution of solute within hydrogel matrices during swelling processes are very complicated to elucidate. Further, gel swelling and shrinking is anisotropic causing inhomogeneous concentration distributions of polymers segments constructing the gel during various states of swelling. This phenomenon presumably leads to structural changes within the gel, and strongly influences a release rate change or on-off release mechanism. In this paper, we discuss the on-off release mechanism of such IPN networks, relating this phenomena to swelling-shrinking kinetics, and we have constructed a model of the on-off drug release mechanism.

\section{MATERIALS AND METHODS}

\section{Materials}

Acrylamide (AAm), acrylic acid (AAc), butyl methacrylate (BMA), methylene-bis-acrylamide (MBAAm), dimethylsulfoxide (DMSO), and ammonium persulfate (AP) were purchased from Wako Pure Chemical Industries, Ltd. $t$-Butyl peroctanoate (BPO) was supplied from Nippon Oil and Fats Co., Ltd. AAm monomer was recrystallized before use. AAc, BMA, and DMSO were distilled under a 
reduced pressure before use. BPO and AP were used as received.

\section{Synthesis of IPN}

Details regarding the synthesis of IPN networks were published in a previous paper. ${ }^{19}$ The IPN was synthesized by a methods of sequential IPN synthesis. Poly(AAm-co-BMA) gel was synthesized as an initial gel for IPN, and then PAAc gel as a secondary gel was polymerized within initial gel. AAm $(3.2 \mathrm{~g})$, BMA $(0.8 \mathrm{~g})$, MBAAm $(0.0390 \mathrm{~g})$, and BPO $(0.036 \mathrm{ml})$ were mixed and diluted to $20 \mathrm{ml}$ of total volume by DMSO. The monomer solution was poured into a space between two glass plates separated by a gasket spacer (thickness: $0.5 \mathrm{~mm}$ ), and heated at $80^{\circ} \mathrm{C}$ for $24 \mathrm{~h}$. This polymerized initial gel was sufficiently washed in DMSO, DMSO/water mixed solution and distilled water to remove residual unreacted monomers. After drying the initial gel, the dry gel was put into aqueous monomer solution containing AAc (10 wt \%), MBAAm $(0.5 \mathrm{ml} \%)$ and AP $\left(2 \mathrm{gl}^{-1}\right)$ as needed to synthesize the secondary gel. The initial gel was swollen at $10^{\circ} \mathrm{C}$ for $24 \mathrm{~h}$ in the solution. After interposing the gel swollen by secondary monomer component solution between two glass plates with a spacer (thickness: $0.5 \mathrm{~mm}$ ), the gel was heated at $50^{\circ} \mathrm{C}$ for $72 \mathrm{~h}$. The synthesized IPN was analyzed after washing for more than a week in distilled water.

\section{Swelling Measurement}

Disk shaped IPNs (diameter: $15 \mathrm{~mm}$ ) were dried at room temperature for $24 \mathrm{~h}$ and then at room temperature in vacuo for 5 days. After immersion in water at desired temperature for fixed time periods, the sample was removed from water and tapped with filter paper to remove excess water from the sample surface. The polymer sample was then weighed at these fixed times. The weight ratio, $W_{\mathrm{s}} / W_{\mathrm{p}}$, was used to evaluate the swelling ratio, where $W_{\mathrm{s}}$ is weight of absorbed water and $W_{\mathrm{p}}$ is that of the dried polymer disk.
Swelling behaviors of IPN in response to temperature fluctuation were obtained by mutually changing temperatures of water. Two upper- and lower bounded temperature ranges were studied: $30-10^{\circ} \mathrm{C}$ and $30-20^{\circ} \mathrm{C}$. Time courses for swelling ratios were obtained with temperature fluctuations between lower $(1.5 \mathrm{~h})$ and higher $(0.5 \mathrm{~h})$ temperature.

Additionally, swollen IPNs $(25 \mathrm{~mm} \times 10$ $\mathrm{mm}$ ) equilibriated at $30^{\circ} \mathrm{C}$ were put into water at $10^{\circ} \mathrm{C}, 15^{\circ} \mathrm{C}, 20^{\circ} \mathrm{C}$, or $25^{\circ} \mathrm{C}$, respectively, and swelling ratio changes after cooling were observed.

\section{Transmittance $(T \%)$ Measurement}

IPNs in equilibrium swollen states at $30^{\circ} \mathrm{C}$ were transported into distilled water at $10^{\circ} \mathrm{C}$, $15^{\circ} \mathrm{C}, 20^{\circ} \mathrm{C}$, and $25^{\circ} \mathrm{C}$, respectively, and changes of transmittance of the IPN after temperature changes were measured with a visible spectrophotometer at $500 \mathrm{~nm}$.

IPN samples $(25 \mathrm{~mm} \times 10 \mathrm{~mm})$ were adhered to a wall of a glass spectrophotometer cell. The glass cell was filled with distilled water and fixed in the cell holder with a device for water circulation adjusted to desired constant temperature.

\section{Drug Release}

Dried IPN disks (diameter: $15 \mathrm{~mm}$ ) were immersed into ketoprofen ethanol-water $(80: 20$, $\mathrm{v} / \mathrm{v})$ solutions for 5 days. After removing drug from the surface by washing with ethanol, the IPNs were dried at $-20^{\circ} \mathrm{C}$ for $24 \mathrm{~h}$ in vacuo and at room temperature in vacuo for $72 \mathrm{~h}$.

Two flasks filled with distilled water $\left(1 \mathrm{dm}^{3}\right)$ at two different temperatures were arranged for drug release experiments. The IPN device was mutually transported between the two flasks at fixed times and drug was released into the distilled water medium. Amounts of released drug were monitored by measuring the concentration of the medium solution with UV spectroscopy at $258.4 \mathrm{~nm}$.

Furthermore, drug release rate changes in response to temperature change were invest- 
igated by using a flow cell. Media was distilled water and flow rate of media was $1.05 \mathrm{~cm}^{3}$ $\min ^{-1}$. The drug concentration of the solution effused from the cell was continuously monitored with the UV spectrophotometer. The cell was put into water bath fixed at desired temperature, and mutually transported between two water baths to change temperature of flow cell.

\section{RESULTS AND DISCUSSION}

\section{Drug Release from IPN Networks}

Figures 1 and 2 show swelling changes and ketoprofen release profiles of the IPN, respectively, in response to temperature change using the different temperature intervals: $10-30^{\circ} \mathrm{C}$ and $20-30^{\circ} \mathrm{C}$.

PAAc and PAAm form polymer complexes

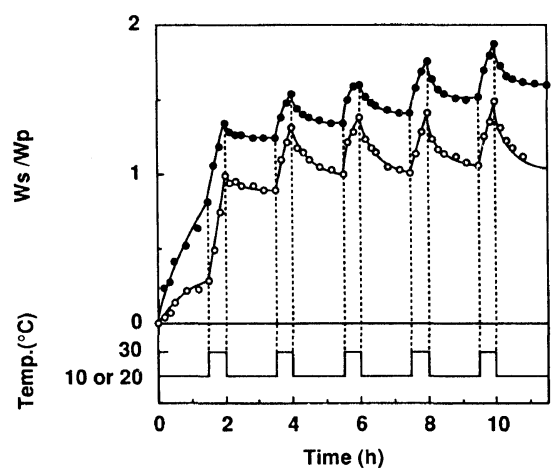

Figure 1. Swelling changes of IPN-20 in response to step-wise temperature changes. Key: $(\mathrm{O})$, between $10^{\circ} \mathrm{C}$ and $30^{\circ} \mathrm{C}$; (O), between $20^{\circ} \mathrm{C}$ and $30^{\circ} \mathrm{C}$.

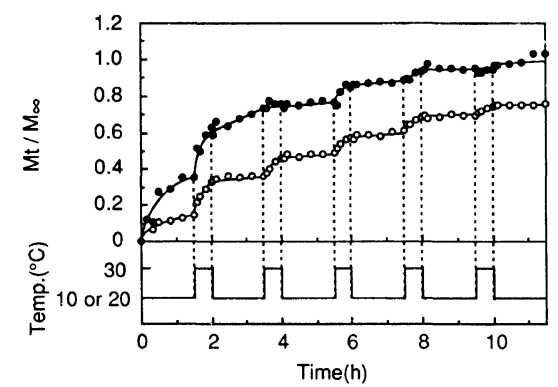

Figure 2. Ketoprofen release profiles from IPN-20 in response to step-wise temperature changes. Key: $(\mathrm{O})$, between $10^{\circ} \mathrm{C}$ and $30^{\circ} \mathrm{C} ;(\mathrm{O})$, between $20^{\circ} \mathrm{C}$ and $30^{\circ} \mathrm{C}$. by hydrogen bonding at lower temperatures, and the polymer complex formation causes dehydration and precipitation of polymers. These phenomena cause shrinkage of IPN. On the other hand, the polymer complex dissociates and dissolves at higher temperatures because of breakage of hydrogen bonds, resulting in swelling of IPN gels. The transition between the two gel states-shrinking state and swelling state - is related to a drastic alteration between the two polymer chain states, complex formation and complex dissociation, induced by a zipper-like formation/dissociation mechanism. ${ }^{19}$ The IPNs change their swelling ratios in response to temperature fluctuations. The reversible swelling changes can be induced by reversible formation-dissociation changes in the polymer complex with temperature change.

Although both swelling profiles in Figure 1 show a trend of reversible swelling changes, quantitative values of $W_{\mathrm{s}} / W_{\mathrm{p}}$ at each time were different from each other. For the profiles with $20-30^{\circ} \mathrm{C}$ fluctuation, the IPN does not reach the original swelling ratio in shrinking process before swelling processes were started, and then overall swelling demonstrates a tendency to increase its swelling ratio in consequent repetition of temperature fluctuations. This tendency is attributed to low degree of complexation at $20^{\circ} \mathrm{C}$. In the case of temperature fluctuation between $20^{\circ} \mathrm{C}$ and $30^{\circ} \mathrm{C}$, quantity of complex formation at $20^{\circ} \mathrm{C}$ is smaller than that of complex dissociation at $30^{\circ} \mathrm{C}$. This quantitative imbalance between formation and dissociation of the polymer complex probably causes this trend. For the case of the $10-30^{\circ} \mathrm{C}$ temperature change, this imbalance of changes between swelling and shrinking processes, neglecting the first cycle, is smaller, in contrast to the case of the $20-30^{\circ} \mathrm{C}$ temperature fluctuation. More effective complexation of polymer and more complete contraction of gel can be expected at lower temperature.

Regarding the drug release profile in Figure 2 , release rate changes are observed with 
changing temperature in both cases. For the case of the $10-30^{\circ} \mathrm{C}$ temperature change, "off" release is consistently observed at $10^{\circ} \mathrm{C}$ (disregarding the first cycle), although the case of $20-30^{\circ} \mathrm{C}$ does not ever show a clear "off" state at $20^{\circ} \mathrm{C}$. The amount of released drug at any time in the case of $10-30^{\circ} \mathrm{C}$ changes is smaller than that of the another case. Connecting release profiles to swelling behaviors, higher release rates at $20^{\circ} \mathrm{C}$ than that at $10^{\circ} \mathrm{C}$ in the first or second cycles seems to be due to higher swelling ratios at the former temperature.

For the case of the $10-30^{\circ} \mathrm{C}$ change, swelling changes for IPNs at $10^{\circ} \mathrm{C}$ during the first cycle $(0-1.5 \mathrm{~h})$ is smaller than that seen at $20^{\circ} \mathrm{C}$, and drug release during the period at $10^{\circ} \mathrm{C}$ is due only to drug on the device surface. Drug release behavior shows "on" release at $30^{\circ} \mathrm{C}$ and "off" release at $10^{\circ} \mathrm{C}$ with temperature fluctuation. The "on" release and "off" release occur during swelling process and shrinking process, respectively. It is remarkable that "off" release is achieved as soon as temperature is changed. This result suggests that equilibrium shrunken state is not necessarily needed to achieve "off" release. The "off" release mechanism may be related to the dynamics of the shrinking mechanism of IPN,

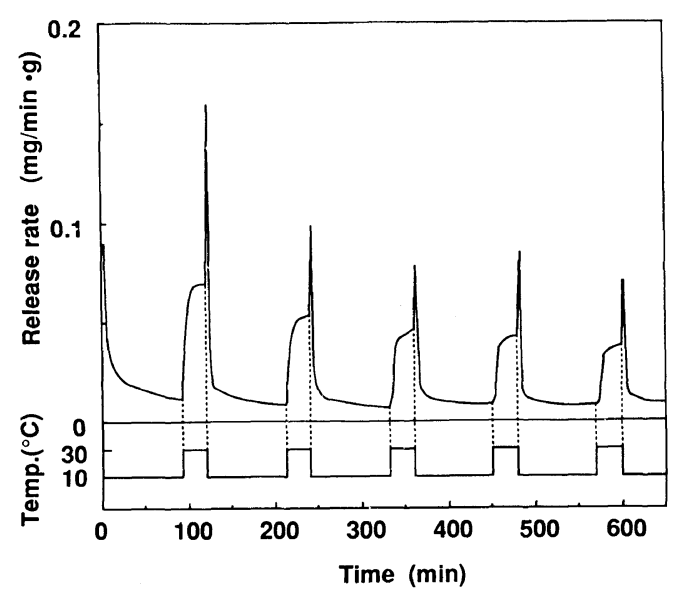

Figure 3. Change of drug release rate from IPN-20 in response to step-wise temperature change between $10^{\circ} \mathrm{C}$ and $30^{\circ} \mathrm{C}$ in distilled water. not its equilibrium configuration.

It is difficult to discuss release mechanisms by using only release profile data shown in Figure 2 and swelling changes shown in Figure 1. To perform continuous drug release monitoring, amount of release drug was measured using a flow cell. This measurement of release rate using the flow cell makes it possible to discuss the mechanism of "off" and "on" release processes in greater detail.

Release rate changes in response to tempera-

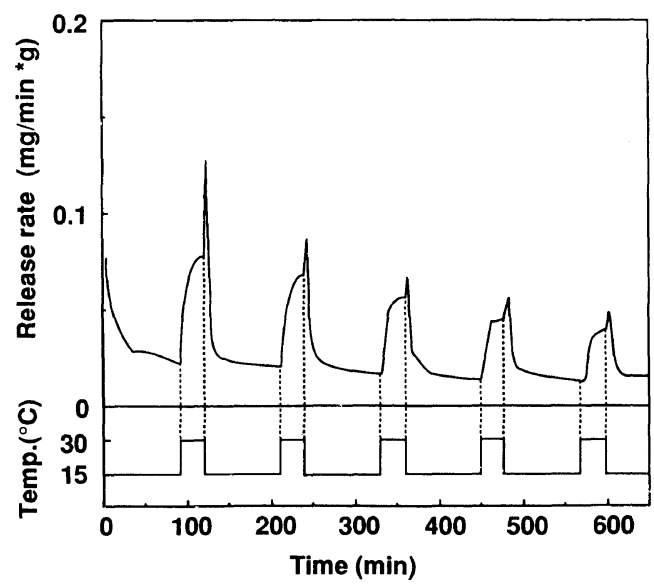

Figure 4. Change of drug release rate from IPN-20 in response to step-wise temperature change between $15^{\circ} \mathrm{C}$ and $30^{\circ} \mathrm{C}$ in distilled water.

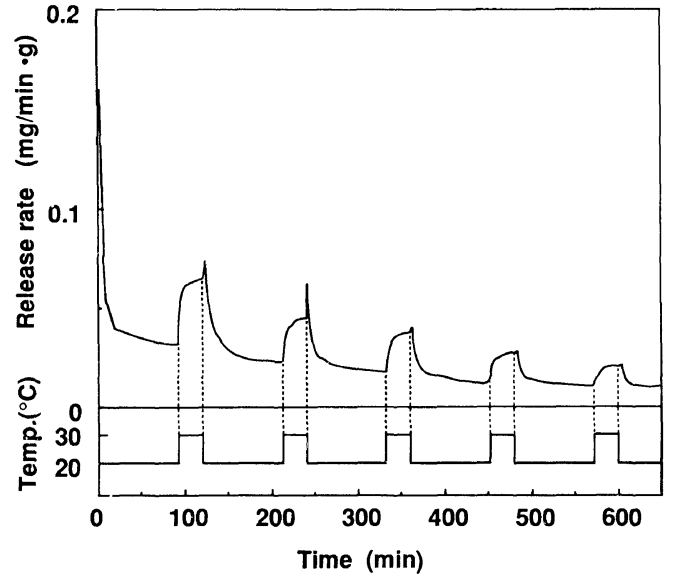

Figure 5. Change of drug release rate from IPN-20 in response to step-wise temperature change between $20^{\circ} \mathrm{C}$ and $30^{\circ} \mathrm{C}$ in distilled water. 
ture changes between $30-10^{\circ} \mathrm{C}, 30-15^{\circ} \mathrm{C}$, and $30-20^{\circ} \mathrm{C}$ are shown in Figures $3-5$, respectively. The release rate changes from poly(hydroxyethyl methacrylate) (PHEMA) gel is also shown in Figure 6 as a control which does not demonstrate any swelling changes against temperature change $\left(W_{\mathrm{s}} / W_{\mathrm{p}} \sim 0.6\right)$. All release profiles show high release rates at higher temperature and lower release rates at lower temperatures. Release rate at lower temperatures increases with increase in the lower bound of the temperature fluctuation. Release rates at $30^{\circ} \mathrm{C}$ decay faster for the IPN with smaller temperature intervals. Some profiles show sharp peaks soon after cooling.

It is worth noting that sharp peaks are observed soon after temperature changes from, for example, $30^{\circ} \mathrm{C}$ to $10^{\circ} \mathrm{C}$. The peak becomes unclear with decrease in the temperature interval. PHEMA gel does not show the large peaks shown in Figure 3.

IPNs shrink gradually after temperature is reduced from $30^{\circ} \mathrm{C}$ to $10^{\circ} \mathrm{C}$ or $20^{\circ} \mathrm{C}$, without any drastic change. Release rates, however, demonstrate an immediate increase soon after temperature reduction to $10^{\circ} \mathrm{C}$, followed by consecutive steep rapid decrease, and a final constant low release rate. The relationship between shrinking profile and off release profile

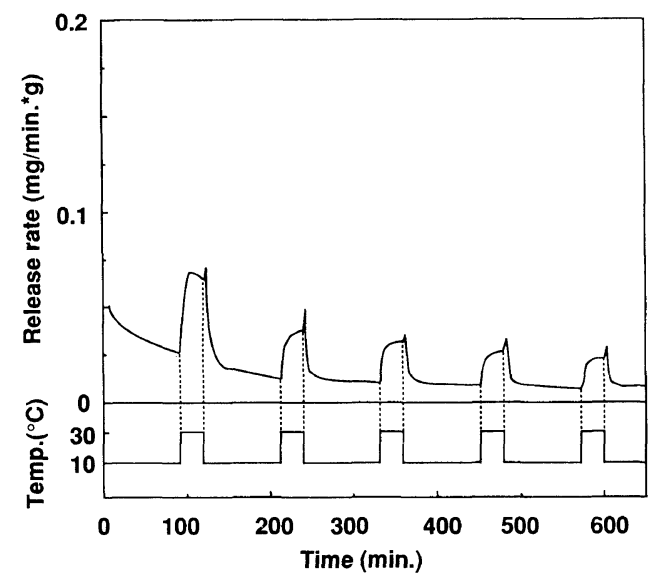

Figure 6. Change of drug release rate from cross-linked PHEMA in response to step-wise temperature change between $10^{\circ} \mathrm{C}$ and $30^{\circ} \mathrm{C}$ in distilled water. suggests that switching of on-off release does not necessarily require a large total swelling change. A phenomenon occuring primarily at the IPN surface seems to rather significantly relate to the "off" mechanism. Steep rate increases probably result from drug mechanically forced to release by IPN surface shrinkage, not from diffusively released drug. Larger peaks are observed for cases with larger temperature gaps in temperature fluctuation. This tendency indicates that peak size reflects an ability for surface layers to shrink effectively at the surface. The phenomena may be elucidated by studying the mechanism of gel shrinking.

\section{Shrinking Mechanism}

IPN gels in swollen states exhibited translucency and the degree of turbidity change depended upon temperature according to the miscibility of polymeric matrices with water. Although IPNs showed high swelling, they maintained enough mechanical strength to use as a release device.

IPNs were also observed to become turbid from an originally translucent state soon after cooling, and then gradually became translucent again at the lower temperature. To investigate these phenomena in detail, change of transmittance, $T \%$, of the IPN after cooling was measured. Figure 7 shows changes of transmit-

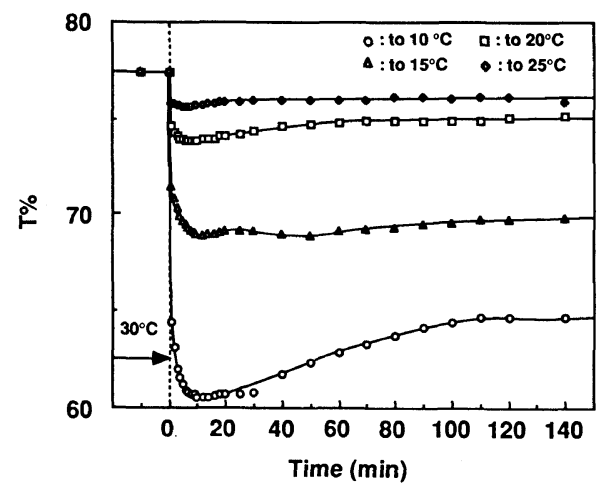

Figure 7. Time courses of transmittance changes of IPN-20 after temperature changes from $30^{\circ} \mathrm{C}$ to $10^{\circ} \mathrm{C}(\mathrm{O})$, $15^{\circ} \mathrm{C}(\triangle), 20^{\circ} \mathrm{C}(\square)$, and $25^{\circ} \mathrm{C}(\diamond)$. 
tance of IPN after cooling from $30^{\circ} \mathrm{C}$ to $10^{\circ} \mathrm{C}$, $15^{\circ} \mathrm{C}, 20^{\circ} \mathrm{C}$, and $25^{\circ} \mathrm{C}$. Transmittance steeply decreases soon after temperature change in all cases. All profiles show a minimum at around 10 min. Larger change is observed with larger temperature intervals.

Further, IPN swelling changes under the same conditions with $T \%$ measurement were also measured, and are shown in Figure 8. Swelling ratios demonstrate rather gradual changes compared with $T \%$ changes.

Although both transmittance and swelling ratios show tendencies to decrease after

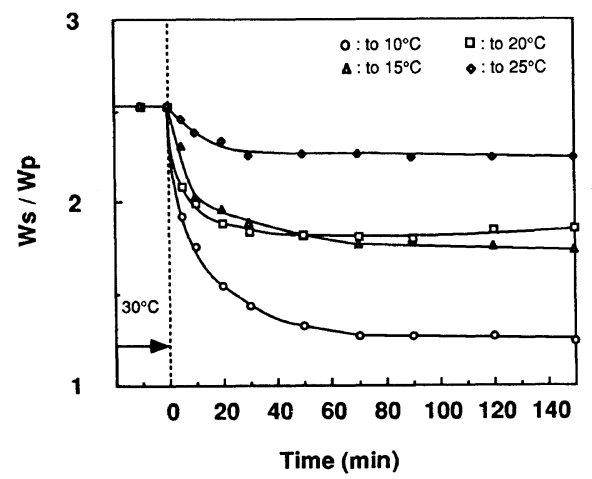

Figure 8. Time courses of swelling changes of IPN-20 after temperature changes from $30^{\circ} \mathrm{C}$ to $10^{\circ} \mathrm{C}(\mathrm{O}), 15^{\circ} \mathrm{C}$ $(\triangle), 20^{\circ} \mathrm{C}(\square)$, and $25^{\circ} \mathrm{C}(\diamond)$. cooling, the profiles indicate different shapes relative to each other. Analyzing the two profiles may lead to an elucidation of a shrinking mechanism. Therefore, to discuss the mechanism comparing the two profiles, the profiles with temperature changes from $30^{\circ} \mathrm{C}$ to $10^{\circ} \mathrm{C}$ are plotted in one graph as shown in Figure 9. The figure implies that the two behaviors change in two different manners against time. We can speculate a shrinking mechanism for the IPNs by relating the two behaviors. A drastic drop in transmittance seems to result from interruption of light

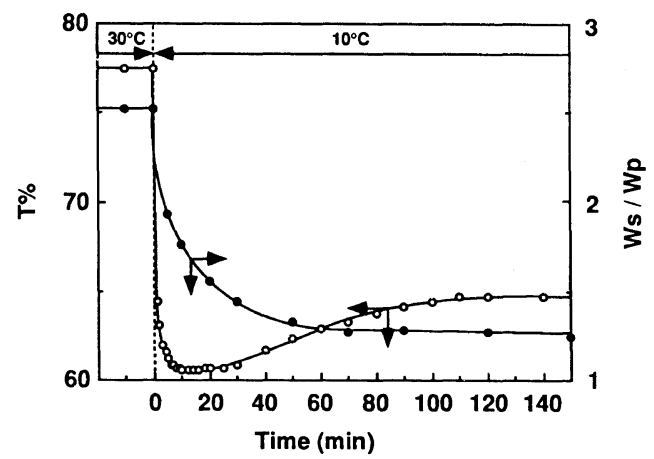

Figure 9. Time courses of changes of swelling ratio of IPN-20 and transmittance through the gel after temperature change from $30^{\circ} \mathrm{C}$ to $10^{\circ} \mathrm{C}$.
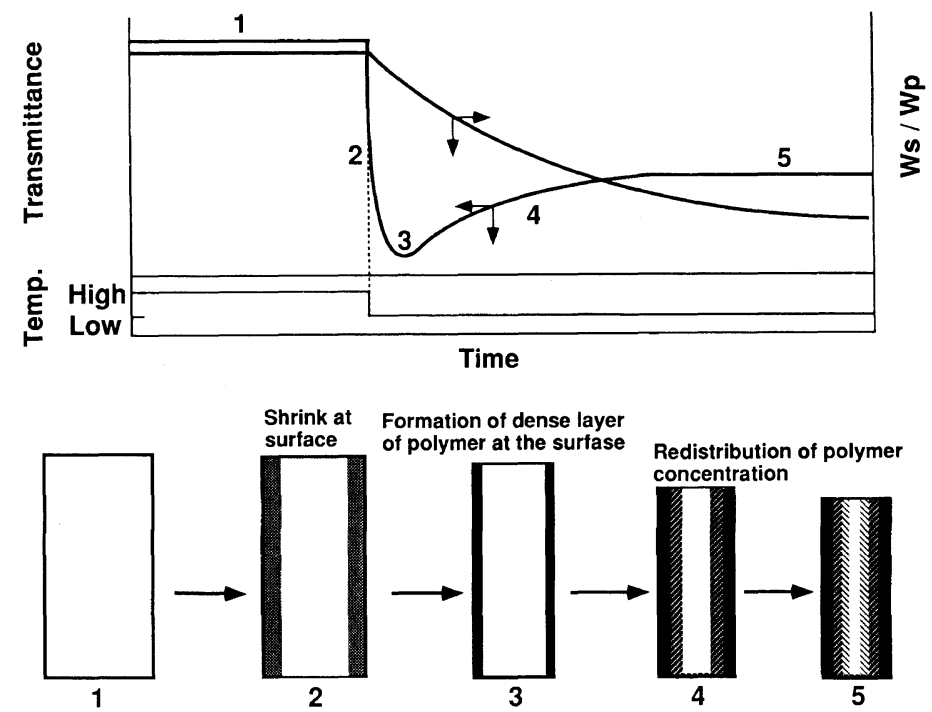

Figure 10. Model for shrinking mechanism of IPN. 
transmittance by two factors: one is precipitation of polymers and the other is a widespread inhomogeneity of polymer concentration induced by inhomogeneous shrinkage. The transmittance, in fact, simultaneously starts decreasing as volume change is initiated. We have hypothesized a model as shown in Figure 10 to explain the shrinking mechanism. IPNs start to shrink due to complexation of polymers soon after cooling. The complexation induces precipitation of polymer and decreases $T \%$. However, the complexation does not occur homogeneously and is kinetically dependent upon convection and conduction within and throughout the gel matrix. The complexation starts from surface which initially contacts the cooled aqueous external environment and the complexation causes dehydration, leading to concentrated polymer states only at the IPN surface in initial stages. Therefore, differences in polymer concentration between the gel interior and gel surface causes an inherent inhomogeneity of polymer segment concentration. This phenomena also induces a turbid state. Therefore, we propose that there are two factors causing turbidity, one is precipitation of polymer and the other is inhomogeneity of polymer concentration. These two factors work simultaneously soon after cooling and the IPN becomes initially turbid, shown by process 2 in Figure 10. The minimum in transmittance implies a state when the polymer concentration gap between its interior and its surface is the largest (process 3). As gel shrinkage proceeds, the polymer concentration distribution alters from discrete discontinuity to gradual gradients because water inside the gel is compeled to flow out by gel shrinkage and the equilibrium polymer network becomes completely concentrated. The transmittance slope further decreases and the concentration distribution approaches homogeneity. The difference in shrinking rate between the IPN surface and its interior causes such $T \%$ behavior.

Okano and coworkers have reported a gel shrinking mechanism for PIPAAm gels using microscopic data. ${ }^{21}$ PIPAAm shrinks at its surface initially and then forms a dense polymer layer at the surface. Furthermore, bubbles of polymer skin appear on the surface. They explain these phenomena by claiming that the water prevented from flowing out is forced to press against the dense layer from gel's inner side by a pressure induced by gel shrinking, and the interior pressure against the dense layer makes the bubble at the surface. The PIPAAm gel also shows abrupt shrinking at its surface soon after cooling and the dense surface layer significantly influences the total shrinking (equilibrium) behavior of the gel. IPNs similarly form dense surface layers soon after cooling caused by inhomogeneous complexation. The inhomogeneous polymer-density gradient gradually alters to a homogeneous state as shrinking proceeds.

\section{Release "off" Mechanism of IPN Networks}

Release rate is principally dominated by drug solubility and drug diffusivity in polymeric matrices. The solubility and diffusivity of drug are both functions of temperature. Therefore, the temperature dependences of the two factors must be taken into account for drug release systems using temperature change as a stimulus. Further, diffusion changes of drugs in gels are dominated by free volume changes of the gel. Therefore, drug release rates may also be controlled by changing swelling ratios. Observed release rates in the temperaturedependent hydrogels at a certain temperature is determined by a combination of drug solubility, drug diffusivity, and swelling ratio of the gel at that temperature.

Drug release from PHEMA gel in Figure 6 shows a high release rate at $30^{\circ} \mathrm{C}$ and low release rate at $10^{\circ} \mathrm{C}$. The release rate difference between that at $10^{\circ} \mathrm{C}$ and that at $30^{\circ} \mathrm{C}$ is not due to free volume change effects because PHEMA gel shows approximately a constant swelling ratio (0.6) regardless of temperature. Release rate changes from PHEMA is considered to depend mainly on temperature de- 
pendence of solubility and diffusivity of drug. The release rate at $30^{\circ} \mathrm{C}$ is about 2.5 times that at $10^{\circ} \mathrm{C}$. Solubilities of ketoprofen are $0.16 \mathrm{mg} \mathrm{ml}^{-1}$ and $30^{\circ} \mathrm{C}$ and $0.09 \mathrm{mg} \mathrm{ml}^{-1}$ at $10^{\circ} \mathrm{C}$, i.e., solubility at $30^{\circ} \mathrm{C}$ is 1.8 times that at $10^{\circ} \mathrm{C}$. It is generally reported that diffusivity increases with increasing temperature, depending on the magnitude of the activation energy which needs to be overcome by thermal energy. ${ }^{13}$ Therefore, release rate is considered to increase with increasing temperature by the effect. In the case of release from PHEMA gel, release rate change with temperatures is due to the positive influence on drug solubility and diffusion of temperature increase. Using these two factors, release rates may be controlled to a certain degree.

However, we can observed some remarkable differences between IPN and PHEMA behaviors. IPN release rates at $30^{\circ} \mathrm{C}$ are approximately 4 times that at $10^{\circ} \mathrm{C}$. IPNs show a sharp peak after cooling and maintain low release rates. These phenomena are explained by the effect of large swelling changes in IPNs.

Shrinking processes of gels seem to relate strongly to release rate peak appearances. In a previous section, dense surface layers were proposed to form with temperature reduction from $30^{\circ} \mathrm{C}$ to $10^{\circ} \mathrm{C}$. Noting surface conditions, the drug in the surface layer is probably forced out of the gel i.e., the drug is mechanically squeezed from surface layer (squeeze effect). For the case of cooling, for example, from $30^{\circ} \mathrm{C}$ to $20^{\circ} \mathrm{C}$ (Figure 5), the peak after cooling is smaller compared to that for the change from $30^{\circ} \mathrm{C}$ to $10^{\circ} \mathrm{C}$ (Figure 3). In this case, it may be assumed from the small $T \%$ change that surface shrinkage is not significant enough to cause a large squeeze effect. From the comparison between Figures 3 and 5, peak appearance is considered to be significantly related to the degree of squeezing by surface shrinking.

Details of the release on-off mechanism from IPN networks are shown schematically in a model in Figure 11. At high temperature, drug is released by diffusion through the gel matrix in a swollen state. As the gel is cooled, local shrinkage occur immediately at surface and the shrinkage forces drug in surface layer out of the gel, resulting in rapid release rate increase. At the next stage, formation of the shrinking surface layer plays a role of an impermeable barrier to prevent drug release, resulting in an

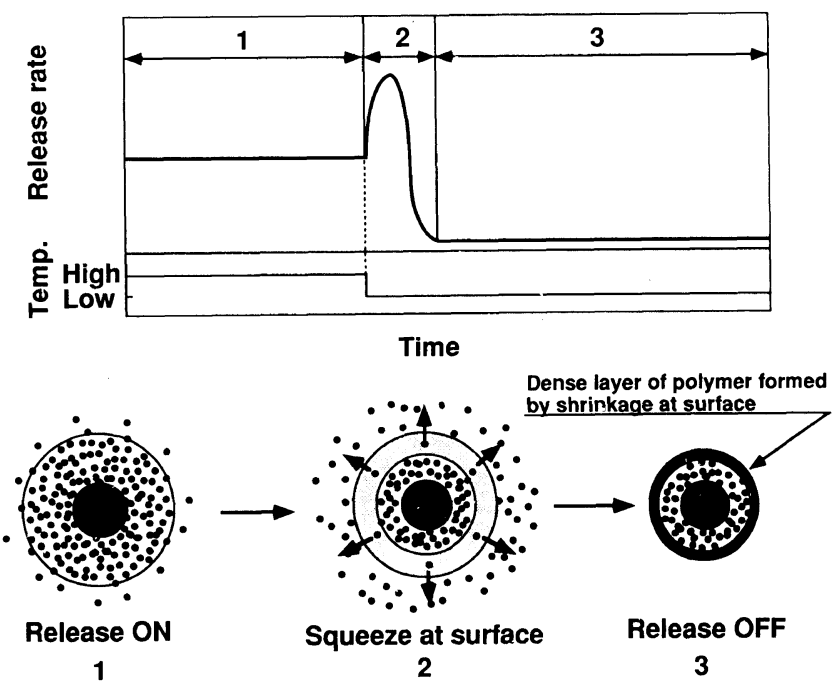

Figure 11. Release rate change of drug from ON state to OFF state in IPN devices correlated to corresponding physical states of IPNs. 
abrupt fall in release rate. Due to the disturbance by the surface layer, a low basal release rate can be maintained after peak appearance. On the other hand, for the case that surface shrinkage is small, squeezing of drug cannot occur because shrinkage is not significant enough to repel drug from the matrix. Even after cooling, drug release is not inhibited at low temperature because the dense surface layer does not impose a complete barrier to prevent drug release. This model suggests that rapid change from "on" state to "off" state of drug release is accomplished mainly by a rapid dense surface layer formation which can disturb drug release completely.

Formation of surface shrinking layer in IPNs can cause characteristic features such as drug squeezing, release restraint, "off" switching and a redistribution of drug concentration gradients within the gel. Regulation of the layer formation rate, thickness and density of the dense surface layer is expected to make characteristic on-off release possible.

Although the model was produced after considering all results mentioned above, we have neglected the thickness and density of the dense layer in terms of quantitative evaluation. This is because detailed data concerning the layer characterization does not permit adequate determination. For quantitative discussion about the structural effects of surface shrinking layer formation, further investigations are needed. We conclude so far in this paper that the drastic swelling changes at the surface may be used to achieve stimuliresponsive hydrogels as thermo-switches for regulating on-off transportation of solutes.

Okano's group has reported a thermo-responsive on-off drug release mechanism related to swelling behavior of PIPAAm gels. ${ }^{22-24}$ They, furthermore, discussed drug concentration distribution within "off" state gels including water. Drug concentration gradients generated by drug release reportedly redistribute via drug diffusion within the off state gel. By allowing enough equilibriation time during "off" stages, drug concentration gradients in the gel become even and reestablishes a homogeneous distribution. Drug redistribution creates an observable, rapid release rate as soon as temperature is changed again.

\section{CONCLUSION}

Release "off" switching mechanisms for IPNs may be explained in relation to gel shrinking processes, as follows;

1. In shrinking processes, shrinking starts from the IPN surface soon after cooling. This phenomenon causes an inhomogeneous surface shrinking condition.

2. There is a most inhomogeneous condition in the gel, exhibiting the largest shrinking degree gradient between the surface and the gel interior at a certain time point.

3. At this point, shrinking proceeds with distributional changes in polymer concentration (inhomogeneity). The shrinking state changes from an inhomogeneous condition mentioned above to homogeneous condition, i.e., equilibrium swelling state at each temperature as deswelling advances throughout the gel.

4. Mechanical squeezing of drug within surface layer occurs simultaneously with surface shrinking soon after cooling, resulting in drastic rate increase of drug release.

5. Reduction of release rate after the rate increase corresponds to rapid barrier formation which disturbs and hinders drug release. A dense polymer skin quickly formed by surface shrinkage plays a role as a barrier to prevent external drug release. In this state, therefore, the IPN keeps an "off" state.

Acknowledgement. The authors would like to thank David Grainger, Ph, D, Assistant Professor of Oregon Graduate Institute of Science and Technology, for revising and enhancing the quality of the manuscript. 


\section{REFERENCES}

1. R. A. Siegel and B. A. Firestone, Macromolecules, 21, 3254 (1988).

2. T. Tanaka, I. Nishio, S.-T. Sung, and S. U-Nishio, Science, 218, 467 (1982).

3. K. Ishihara, M. Kobayashi, N. Ishimaru, and I. Shinohara, Polym. J., 16, 625 (1984).

4. I. Ohmine and T. Tanaka, J. Chem. Phys., 77, 5725 (1982).

5. T. Tanaka, Phys. Rev. Lett., 40, 820 (1978).

6. A. Hochberg and T. Tanaka, Phys. Rev. Lett., 43, 217 (1979).

7. T. Tanaka, D. Fillmore, S.-T. Sung, I. Nishio, G. Swislow, and A. Shah, Phys. Rev. Lett., 45, 1636 (1980).

8. Y. Hirokawa and T. Tanaka, J. Chem. Phys., 816379 (1984).

9. Y. Hirokawa, T. Tanaka, and S. Katayana, "Microbal Adhesion and Aggregation at Dahlem Konferenzen," K. C. Marshall, Ed., SpringerVerlag, Berlin, 1984, pp. 177-188.

10. Y. H. Bae, T. Okano, and S. W. Kim, J. Polym. Sci., 28, 923 (1990),

11. Y. H. Bae, T. Okano, and S. W. Kim, Makromol. Chem., Rapid Commun., 9185 (1988).

12. Y. H. Bae, T. Okano, R. Hsu, and S. W. Kim, Makromol. Chem., Rapid Commun., 8, 481 (1987).
13. Y. H. Bae, T. Okano, and S. W. Kim, J. Control. Rel., 9, 271 (1989).

14. T. Okano, Y. H. Bae, H. Jacobs, and S. W. Kim, $J$. Control. Rel., 11, 255 (1990).

15. K. Mukae, Y. H. Bae, T. Okano and S. W. Kim, Polym. J., 22206 (1990).

16. K. Mukae, Y. H. Bae, T. Okano, and S. W. Kim, Polym. J., 22250 (1990).

17. R. Yoshida, T. Okano, K. Sakai, and Y. Sakurai, BME, 4, 23 (1990).

18. T. Okano, Y. H. Bae, and S. W. Kim, " Temperature-responsive Controlled Drug Delivery," in Pulsed and Self-regulated Drug Delivery, Florida, J. Kost, Ed., CRC Press, N. N. Boca Raton, Florida 1990.

19. H. Katono, A. Maruyama, K. Sanui, N. Ogata, T. Okano, and Y. Sakurai, J. Control. Rel., 16, 215 (1991).

20. O. V. Klenina and E. G. Fain, Polym. Sci. U.S.S.R., 23, 1439 (1981).

21. T. Okano, Y. H. Bae, and S. W. Kim, J. Sur. Sci. Soc. Jpn.,10, 90 (1989).

22. R. Yoshida, K. Sakai, T. Okano, and Y. Sakurai, Jpn. J. Artificial Organs, 19, 1243 (1990).

23. R. Yoshida, K. Sakai, T. Okano, and Y. Sakurai, Kagaku Kogaku, 54, 919 (1990).

24. R. Yoshida, K. Sakai, Y. Taguchi, R. Kondo, and Sakurai, Drug Delivery Systems, 5279 (1990). 